\title{
The complexity of online collaborative writing ${ }^{1}$
}

\author{
Vera Lúcia Menezes de Oliveira e Paiva \\ Universidade Federal de Minas Gerais \\ vlmop@veramenezes.com
}

\begin{abstract}
This paper focuses on collaboration, collective intelligence, and wiki technology in a complex perspective. It presents some results from qualitative research carried out with Brazilian university students using wiki tools to write collaborative essays. The results demonstrate that the use of wiki did not change the behavior of the majority of participants because they resisted collaboration, which is considered an essential element for the dynamicity of a complex learning system.
\end{abstract}

Keywords: dynamic systems, collaboration, wiki.

\section{Resumo}

Este trabalho foca a colaboração, a inteligência coletiva e a tecnologia wiki em uma perspectiva complexa. Apresenta resultados de uma pesquisa qualitativa com alunos universitários brasileiros, usando ferramentas wiki para escrita de textos de forma colaborativa. Os resultados demonstram que o uso de wiki não mudou o comportamento da maioria dos participantes porque eles resistiram à colaboração que é um elemento essencial para um sistema de aprendizagem complexo e dinâmico.

Palavras-chave: sistemas dinâmicos, colaboração, wiki.

\section{Introduction}

According to sociocultural theory, "people working jointly are able to co-construct contexts in which expertise emerges as a feature of the group" (Lantolf, 2000, p.17), and I believe digital environments are ideal contexts for group work. In this line of thinking, I assume that

1 This paper was supported by Conselho Nacional de Desenvolvimento Científico e Tecnológico (CNPq) and Fundação de Amparo à Pesquisa do Estado de Minas Gerais (FAPEMIG). 
people working together in a wiki platform make up a complex system and that higher quality texts emerge from their collaborative production. The sum of the students' writings makes up a whole, which probably exhibits more quality than their individual texts because of the emergence of a "collective intelligence" (Levy, 1997).

Levy (1997, p.13) explains the concept of collective intelligence as follows:

It is a form of universally distributed intelligence, constantly enhanced, coordinated in real time, and resulting in the effective mobilization of skills. (...) The basis and goal of collective intelligence is the mutual recognition and enrichment of individuals rather than the cult of fetishized or hypostatized communities.

Levy's premise is "the notion of a universally distributed intelligence. No one knows everything, everyone knows something, all knowledge resides in humanity" (LEVY, 1987, p.13-14).

Malone (2008, p.1) provides a simple and operational definition. He defines collective intelligence as "groups of individuals doing things collectively that seem intelligent." A good example of collective intelligence provided by Malone is Google. He explains that it "takes the collective knowledge created by millions of people making websites for other purposes and harnesses that collective knowledge - using some very clever algorithms and sophisticated technology - to produce amazingly intelligent answers to the questions we type in" (p.1).

In the educational field, group work can be a good example of the exercise of collective intelligence. We expect that people thinking and working together scaffold each other, share expertise, and overcome difficulties. The hypothesis is that when students write together, they work not only as writers, but also as tutors and editors, and it is expected that collaborative texts will gain in quality.

But do students collaborate as expected when writing together with wiki technology? To answer this question, I conducted qualitative research with undergraduate students who are pre-service English teachers. 
In the next sections, I explain what a wiki is and present the research description and results.

\section{What is a wiki?}

There is no better way to know what a wiki is than to appeal to its creator, Ward Cunningham, and to his co-author, Bo Leuf, in a book entitled The Wiki way. Cunningham and Leuf (2001, p.14) explain that wiki comes from the Hawaiian word "Wikiwiki (stative verb). Fast, speedy; to hurry, hasten; quick, fast, swift.” They add that

This term turns up in numerous Hawaiian contexts, both formal and casual, in the simple sense "quick" or "informal."

The Wiki Wiki Web server concept, most often called simply "a wiki", originated with Ward Cunningham. A wiki is a freely expandable collection of interlinked Web "pages", a hypertext system for storing and modifying information-a database, where each page is easily editable by any user with a forms-capable Web browser client.

The software was developed in 1994 and the original WikiWikiWeb site was hosted in the Portland Pattern Repository (PPR, found at http://c2.com/cgi/wiki), as informed by Cunningham and Leuf (2001), who also explain that:

Wiki is unusual among group communication mechanisms in that it allows the organization of contributions to be edited in addition to the content itself. By comparison, e-mail and newsgroup postings are automatically organized by a variety of attributes (author, date, subject) defined at the time the contribution is made. Some reader clients further organize contributions into threads by subject, noting to which messages contributions respond. Although readers can select attributes to organize contributions, they can't further refine the organization to communicate additional information-it is a fixed structure. Wiki supports an arbitrary, changeable, "directed network" (hypertext) organization of its content (p.15). 
According to Bo and Cunningham (2001), users can easily create and edit pages in a wiki Web site. They add that "[a] wiki is not a carefully crafted site for casual visitors. Instead, it seeks to involve the visitor in an ongoing process of creation and collaboration that constantly changes the Web site landscape" $(\mathrm{p}, 16)$, In summary, as defined by Cummings (2008, p.5) "a wiki is a Webpage that users can modify."

In my opinion, the best example of wiki collaboration and the emergence of collective intelligence is the Wikipedia, the universal encyclopedia which has been under constant construction since 2001 through universal collaboration in a wide range of languages. According to Wikipedia, in the entry History": "As of April 2014, Wikipedia includes over 31.3 million freely usable articles in 287 languages that have been written by over 45 million registered users and numerous anonymous contributors worldwide."

The same technology employed by this world encyclopedia can be used in education contexts. Wikis are welcome into education because they afford collaboration, which is an expected skill for the citizens of this century. As Lund (2008, p.36) claims: "collaborative practices are increasingly seen as keys to going beyond what we know and developing the capacity to solve complex problems that are typical of the knowledge society but beyond the capacity of the individual."

Cunningham (2014) acknowledges that Wiki has turned out to be much more than he had imagined and presents the following design principles he sought to satisfy with the first release of Wiki:

- Simple - easier to use than abuse. A wiki that reinvents HTML markup ([b]bold $[/ b]$, for example) has lost the path!

- Open - Should a page be found to be incomplete or poorly organized, any reader can edit it as they see fit.

- Incremental - Pages can cite other pages, including pages that have not been written yet.

\footnotetext{
2 Available at http://en.wikipedia.org/wiki/History_of_Wikipedia. This information was retrieved on April 18, 2014 and as information continues to be updated, new data will probably be found if it is accessed by each reader of this text separately.
} 
- Organic - The structure and text content of the site are open to editing and evolution.

- Mundane - A small number of (irregular) text conventions will provide access to the most useful page markup.

- Universal - The mechanisms of editing and organizing are the same as those of writing, so that any writer is automatically an editor and organizer.

- Overt - The formatted (and printed) output will suggest the input required to reproduce it.

- Unified - Page names will be drawn from a flat space so that no additional context is required to interpret them.

- Precise - Pages will be titled with sufficient precision to avoid most name clashes, typically by forming noun phrases.

- Tolerant - Interpretable (even if undesirable) behavior is preferred to error messages.

- Observable - Activity within the site can be watched and reviewed by any other visitor to the site.

- Convergent - Duplication can be discouraged or removed by finding and citing similar or related content.

\section{Wiki as a complex system}

A Wiki can also be characterized as a complex dynamic system. It is complex because it is made up of interactions among the participants and dynamic because the writing process develops through dynamic interactions which are always in flux. The members of the group can see what the others have done and can collectively edit the same text either in real time or asynchronously. They can discuss the editing and reach a consensus on the final product.

The system is open, that is, it is far from equilibrium, since new content appears, while others are deleted. Participants can edit and change the text at anytime. The posted contributions can also include links to other texts, videos, images, infographics, etc. Depending on 
the reaction of the other writers, the text can also be changed back to a previous stage.

It is adaptive because the system continues to adapt and change. As Bo and Cunningham (2001, p. 392) report: "[i]t would probably be wrong to ever see a wiki implementation as "finished", because the contexts in which it is used are always prone to change. People adapt. Wiki adapts."

The wiki system is considered to be nonlinear, as the effects are not necessarily proportional to the causes. The system changes and the emergent behaviors are not always proportional to the causes. Small contributions can lead to great improvements in the text. On the other hand, the addition of large amounts of texts may not represent a good contribution and might even decrease the quality of the final text. It can, for instance, be repetitive or irrelevant. The system evolves and adapts itself in different ways because it is sensitive to feedback. Members learn from each other. They react to feedback. They learn, they change, and they adapt.

Examples of the effective use of wikis can be found around the world. Elola and Oskos (2010), for instance, report on a study with eight Spanish majors enrolled in an advanced Spanish writing course. They used wiki and their conclusion was:

When working collaboratively, learners realized that the analysis and critique of their ideas enhanced not only the content, but also the overall quality of their essays. Learners became aware that everybody brought to the projects a unique set of skills and that often they could learn more from correcting their partner's grammar and critiquing their ideas than from their own work. In addition, structure and organization improved because the discussions allowed learners to concentrate on a thesis for their essays and support that thesis in a more organized manner.

Kuteeva (2011) also used wikis in a course of Effective Communication in English and concluded that "using the wiki for writing activities made students pay close attention to grammatical correctness and text organization, which are considered by the students to be of utmost importance in determining the quality of writing". She added that "it appears that writing on the wiki can contribute to raising 
students' awareness of the audience, resulting in more reader-oriented texts." (p.55)

Nantel (2008) questions "the dogma that collaboration always produces better results than individual effort. Sometimes it does. Sometimes it doesn't." In fact, in a complex system, unexpected results may appear. Lund (2008, p. 47) warns the following:

However, the broader, collective assignment requires that learners seek to link individual production to the dynamic and collective potential of the wiki. This involves trusting others to contribute productively and developing sensitivity towards the totality by relating one's own contribution to those of others, that is, we see the emergence of a collective $Z P D$.

Judd, Kennedy, and Cropper (2010, p.341) claim that "while wikis include features that are designed to facilitate collaboration, it does not necessarily follow that their use will ensure or even encourage collaborative learning behavior." In their study, they found little evidence of collaboration and contributions were superficial.

As I understand that collaboration is a necessary skill nowadays, I decided to try to motivate students to be more collaborative. My presupposition is that social technological tools, such as wikis, can help students work collaboratively and change their mindsets.

In the next section, I will describe two studies I have conducted on collaboration in the use of wiki technology.

\section{The research}

The participants of the research were students enrolled in undergraduate teacher education online courses in a Brazilian university. The first course - Introduction to digital tools for language teaching - was taught in 2011 and the second - Web tools for language teaching and learning - in 2013. The sixty-hour courses were hosted 
on the learning environment TELEDUC ${ }^{3}$, and the students were required to do individual and group activities, one of which was an essay to be written in a wiki software platform.

\subsection{Course one}

The students were divided into five groups of six participants and one of their tasks was to write an essay in English about "The integration of technology in the English Language classroom." Instructions for the task were posted on the course learning environment and among them, it was included that each student should choose one color for his/her contribution so that the teacher could identify who had written what. It was highlighted that the task was a collective text and everybody was supposed to collaborate.

The students could choose the wiki platform of their preference and had two weeks to write their essays. Each student was asked to use a different color for his/her contribution so that the teacher could identify the dynamicity of each group and the amount of work produced by each participant. The students were warned that everybody was supposed to collaborate and that evaluation would take into account content, quality of collaboration, and participation. It was emphasized that they should post content and edit their classmates' contributions by correcting mistakes and adding further information, exemplifications, and new references.

After analyzing the texts, I noticed that the wiki tools did not promote the expected collaboration, reinforcing what Nantel (2008), Lund (2008, p. 47) and Judd, Kennedy, and Cropper (2010) had already found out. Although students had two weeks to develop a good text, they did not invest enough time to write a real collaborative essay. Four of the six groups exhibited the same writing pattern. Their final products were made up of the juxtaposition of texts in a linear format, one after the other, without any interference in their classmates' texts.

${ }^{3}$ Teleduc is a Brazilian free learning environment software developed at the University of Campinas (Unicamp) in Campinas, São Paulo, Brazil 
In figure 1 , we can see a visual representation of one of the groups that produced a 6-page patchwork text. Five students were in charge of this group, but one did not contribute to the wiki assignment.

Figure 1. Text patchwork

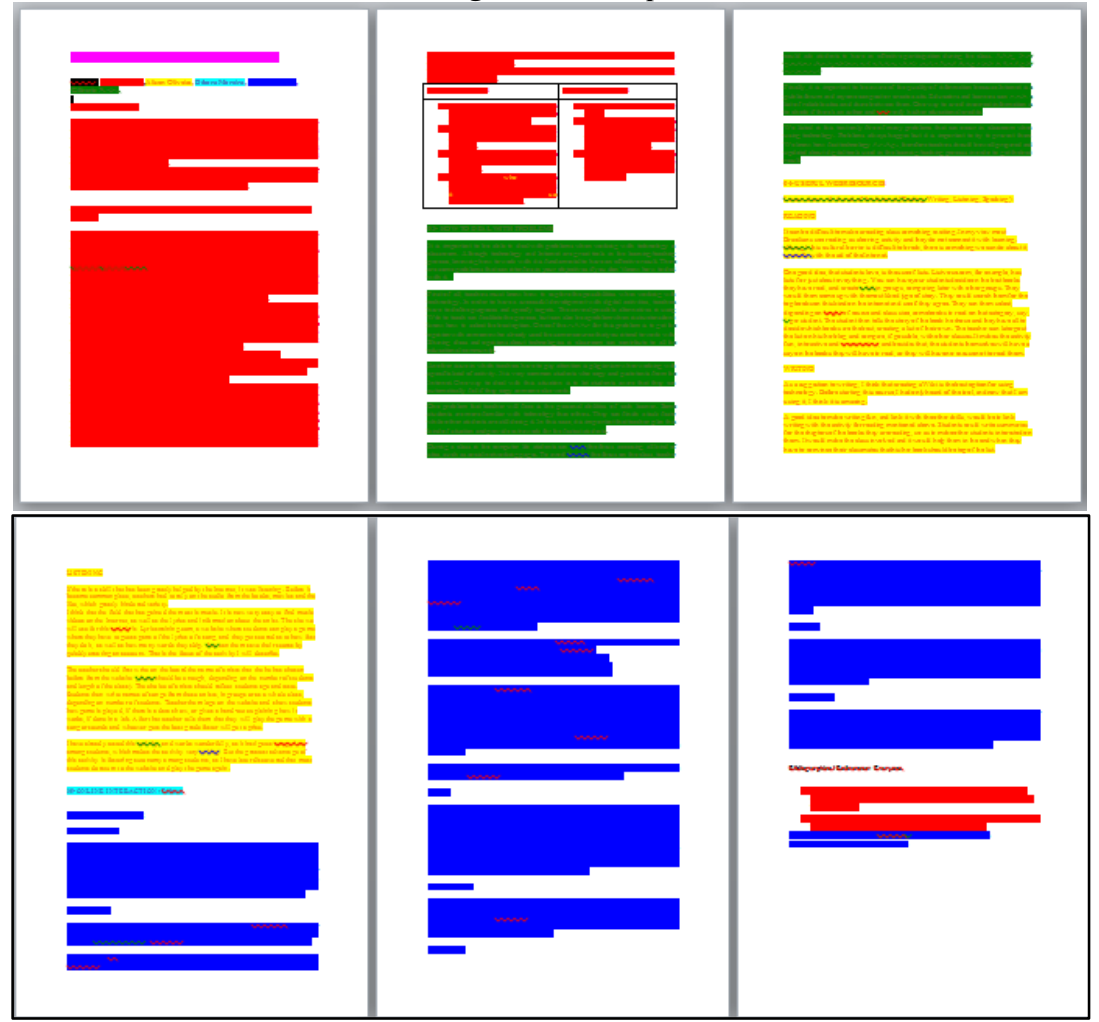

Source: Prepared by the author

When we examine the text produced by this group, we can guess that they had assigned each participant a part. The evidence to this conclusion includes:

(1) the student who did not show up had her name written on page 4 , after the title of section 5 - online interaction although this section had not been developed. The other four students did not worry about completing the task as usually happens in group work. 
(2) the division of labor was explicit in the following note: "Bibliographic References: Everyone", but only two participants posted bibliographic references.

Nevertheless, this group did produce a good text. It showed cooperation, because each was responsible for a section of the essay, but there was no collaboration. Collaboration is understood as mutual engagement and desire to help the others to edit their parts, which did not happen. Although the text is well written, it could have been improved if the instructions had been followed. Unfortunately, there are no marks of editing or corrections. Nobody added more content to his/her classmates' part, no correction was provided, and no one wrote even one line about online interaction. They left section 5 without content, which interfered negatively in the cohesion of the final text and decreased its quality. They should at least have deleted this section, since the instructions had listed suggestions, and the listed sections were not mandatory.

In spite of using a tool that affords interaction and collaboration, most groups produced mere patchworks varying from three to seven pages. Content was usually poor and no real collaboration by means of editing, corrections, and addition of relevant information was detected. Visual representations of the pages showed a sequence of paragraphs in different colors, similar do figure 1, instead of multi-colored paragraphs which would represent real collaboration as in figure 2 .

According to Cunningham and Leuf (2001, p.330), wiki does not work when considering the fact that "[p]age refactorings don't always take place when needed-"refactoring" being a technical term for iterative adjustment based on new input." New input does not mean putting pieces together as a patchwork. Unfortunately, that was what most students did. Some students did not post any contribution at all, and the participants limited themselves to their individual contributions without any commitment to the final product.

A second group followed the same pattern, but as we can track who did what, I realized that there was contribution from one student who had never logged into her wiki group. When I questioned the group, she informed me that she had sent her part by email, which was 
confirmed by the leader of the group. This student neither read nor revised what the others had written.

In the third group, I found that one student had really collaborated by reading the other parts and editing them. He corrected preposition use, verb agreement, and increased the text cohesion, but added no further content.

Real collaboration by means of editing, corrections, and addition of relevant information was detected in only two groups, one of which presented only partial collaboration. Five students wrote 4 pages, and two of them added more information to paragraphs written by their partners, but only one of them made small corrections.

Only one group worked according to the instructions. Although two participants had not collaborated as much as one would expect, the text did show marks of effective collaboration. Their work was a good example of how writing texts can be done in groups in wiki platforms. Figure 2, shows how colors representing different students' writings are intermingled either by adding more information or by editing someone else's text.

Figure 2. Image of collaboration
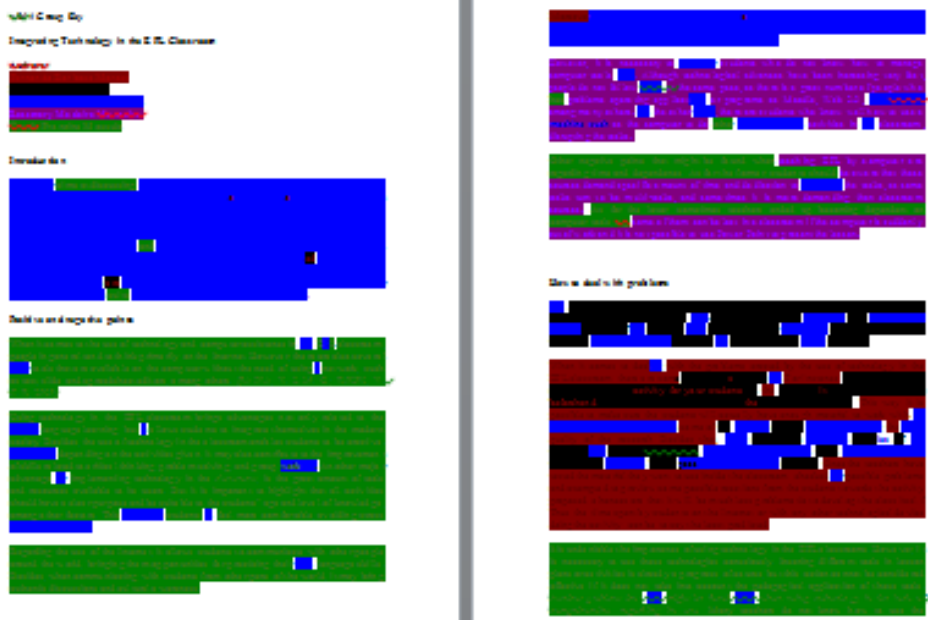

Source: Prepared by the author 
My overall evaluation is that the content of the essays was below my expectations, and expertise did not emerge as a feature of the groups. The results made me consider that one flaw in my course was that I had not discussed the importance of collaboration with the students before asking them to write the collaborative essays. In addition, I was afraid that groups with six students were not a good choice and that smaller groups might work more collaboratively. In addition, I thought that the students would be more motivated to collaborate if they had reflected about collaboration and if they had the chance to choose their partners. I was willing to improve the activity so that it could motivate the students to work collaboratively, which is what I tried to implement in the next course.

\subsection{Course 2}

In 2013, another group of students was enrolled in an online course named Web tools for language teaching and learning. Again, I asked them to work with wiki. The writing activity was preceded by a one-week discussion about collaboration, which took place during three weeks in November.

During the first week, students discussed texts written by D'Andréa and Ribeiro (2012), and Paiva (2012). Their posts in the course forum highlighted the importance of collaboration, and some of the participants said they had used wiki before and that they had appreciated the experience. No objection to the wiki tool was mentioned, and my expectations towards the next activity increased.

This time I chose Google docs, because it is both easy to use and easy for the teacher to track the records of individual participations. I was ready to accept another tool, but they agreed with my choice. The theme to be developed was "Collaboration tools"

Seven groups of four students wrote together using Google Docs. Again, the same patchwork pattern emerged in most groups. Although the students had two weeks to write their wiki, some of them did not work during the first week. Others had not contributed at all or had only included a small paragraph. Two groups exhibited limited editing done by part of the group, and only two groups worked as expected, but their essays had problems. The first essay was 
incomplete, and the second included only references listed in the course. It was obvious that they had not bothered to do research about the topic. Nevertheless, the essay had good content and was the only text to include images.

In one group, I could not find the records of the participation of two students, although their names and excerpts, allegedly written by them, had been incorporated in the final essay. When I asked for an explanation, they told me that they had done everything on one computer logged onto by a third student, which was why their participations were not registered. If that is true, it means that they chose to work together at the same time and using the same computer and did not take advantage of the possibility of working asynchronously. Their text exhibited limited editing, and the prevalent pattern was that of large amounts of text in one color followed by another in a different color. It called my attention that one participant chose to indicate the mistakes in some parts, but the authors did not edit the text. Thus, the final essay had marks, such as "are (IS)" and "have (HAS)", which were ignored. The final paper simply looked like a first draft.

Although they had spent one week reading and discussing about the importance of collaboration and how to work with wikis, their behavior was no different from the students in 2011. Another aspect that called my attention was that they had not included hyperlinks for the collaborative tools, although they had been asked to read a text by Paiva (2012) which focused on the creation of hyperlinks in wikis. I cannot guarantee that the students had read all the texts and watched all the videos, but, if they did, the new knowledge had no impact on their writing habits.

\section{Conclusions}

Many factors might have influenced the outcomes, but this study has demonstrated that the introduction of an online tool which affords asynchrony and collaboration did not contribute to change the students' mindsets. They chose the easiest and fastest way when faced with collaborative tasks. They continued to repeat the usual behavior 
of the division of labor, assigning each participant a section to be developed without any concern as to their partners' parts.

Human complex system can exhibit unexpected behaviors, yet the wiki technology was not enough to change habitual group behaviors or to make the emergence of a collective intelligence possible. Wiki tools may mislead one into thinking that it facilitates the emergence of wholes which are greater than the sum of the individual productions. To use wiki successfully, students' mindsets must change, and they must engage more in collaboration and less in simple cooperation. Digital tools alone do not change culturally rooted practices in our educational system.

Summing up the results of the two interventions suggest that:

1. The wiki tools did not attract the expected collaboration.

2. Students did not invest enough time to write collaboratively.

3. Most students limited themselves to their individual contributions.

4. Few students showed any commitment to the final product.

5. The prevalent text pattern was a patchwork or a juxtaposition of individual texts.

6. Content was usually poor and expertise did not emerge as a feature of the groups.

One limitation of the two studies was that, in both courses, the writing tasks were carried out at the end of the course and, after feedback, the students did not have the chance to write another essay in a wiki platform. I could not evaluate if the group, understood as a complex system, had learned anything from the feedback. Another limitation is that I did not interview the students about their feelings towards that activity, but in informal interactions with some students, they told me they do not like having to work in groups either because they prefer to work alone or because they get annoyed by the delays and absences of some classmates. They usually do not feel comfortable when correcting someone else's texts and added that there are students who do not like to have their contributions edited, deleted, or corrected. With this in mind, I think that further studies should interview students in order to understand the real reasons underlying their resistance in engaging themselves in more collaborative work. 


\section{References}

BO, Leuf ; CUNNINGHAM, Ward. The Wiki way: collaboration and sharing on the Internet. London: Addison Wesley, 2001.

CUNNINGHAM, Ward. Wiki design principles. Available at http://c2.com/cgi/wiki?WikiDesignPrinciples. (last edited March 30, 2014). Access 16 April 2012.

CUMMINGS, Robert E.; BARTON, Matt. (Eds.) Wiki writing: collaborative writing in the college classroom. Ann Arbor: University of Michigan, 2008.

CUMMINGS, Robert E. What was a Wiki, and why do I care? A short and usable history of Wikis. In: CUMMINGS, Robert E.; BARTON, Matt. (Eds.) Wiki writing: collaborative writing in the college classroom. Ann Arbor: University of Michigan, 2008. p.1-16.

D'ANDRÉA, Carlos Frederico, B,; RIBEIRO, Ana Elisa. Produzindo textos em co-autoria no Google docs. IN: RIBEIRO, Ana Elisa; NOVAIS, Ana Elisa C. (Org.) Letramento digital em 15 cliques. Belo Horizonte: RHJ, 2012. p.58-66.

ELOLA, Idoia; OSKOZ, Ana. collaborative writing: fostering foreign language and writing conventions development. Language Learning \& Technology. v. 14, n. 3. p. 51-71. Oct, 2010. Available at http://llt.msu.edu/issues/october2010/elolaoskoz.pdf. Access 15 May 2012.

JUDD, Terry; KENNEDY, Gregor , CROPPER, Simon Using wikis for collaborative learning: assessing collaboration through contribution. Australasian Journal of Educational Technology. n. 26, v. 3, p. 341-354, 2010.

KUTEEVA, Maria. Wikis and academic writing: changing the writerreader relationship. English for Specific Purposes. v. 30, n.1. p. 44-57, 2011. 
LANTOLF, James P. Introducing sociocultural theory. In: LANTOLF, James P. (Ed.), Sociocultural theory and second language learning. Oxford, UK: Oxford University Press, 2000. p. 1-26.

LEVY, Pierre. Collective intelligence: mankind's emerging world in cyberspace. Trans. Robert Bononno. Cambridge, Massachusetts, Helix Books, 1997

LUND, Andreas. Wikis: a collective approach to language production. $\operatorname{ReCALL,~v.~20,~n.~1,~p.~35-54,~} 2008$.

MALONE, Thomas W. What is collective intelligence and what will we do about it? In: TOVEY, Mark (Ed.). Collective intelligence: creating a prosperous world at peace. Oakton, Virginia: Earth Intelligence Network, 2008.

NANTEL, Richard. One thought on "Do crowds really have wisdom?." Available at http://www.brandonhall.com/blogs/do-crowdsreally-have-wisdom/. Access 13 Nov. 2008.

PAIVA, Francis A. Produção de texto em ambiente wiki com edições colaborativas e criações de links. In: RIBEIRO, Ana Elisa; NOVAIS, Ana Elisa C. (Org.) Letramento digital em 15 cliques. Belo Horizonte: RHJ, 2012. p. 104-113.

RIBEIRO, Ana Elisa; NOVAIS, Ana Elisa C. (Org.) Letramento digital em 15 cliques. Belo Horizonte: RHJ, 2012.

Submitted: 28/09/2014

Accepted: 09/01/2015

Título: A complexidade da escrita colaborativa on-line 